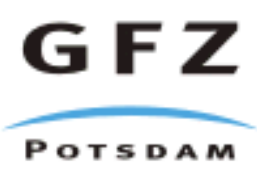

Originally published as:

Naujoks, M., Weise, A, Kroner, C., Jahr, T. (2007): Detection of small hydrological variations in gravity by repeated observations with relative gravimeters. - Journal of Geodesy, 82, 9, 543-553

DOI: 10.1007/s00190-007-0202-9 


\title{
Detection of small hydrological variations in gravity by repeated observations with relative gravimeters
}

\author{
M. Naujoks · A. Weise - C. Kroner · T. Jahr
}

\begin{abstract}
Recently, a new application of timedependent gravity observations is emerging: the study of natural hydrological mass changes and their underlying processes. Complementary to GRACE data and continuous recordings with superconducting gravimeters, repeated observations with relative instruments on a local network may contribute to gain additional information on spatial changes in hydrology. The questions that need to be addressed are whether the results of these repeated measurements will be of sufficiently high resolution and accuracy, as well as how unique the information obtained will be. To examine this, a local gravity network with maximum point distances of $65 \mathrm{~m}$ was established in a hilly area around the Geodynamic Observatory Moxa, Germany. Using three to five LaCoste \& Romberg relative gravimeters repeated measurements were carried out in a seasonal rhythm as well as at particular events like snowmelt or dryness in 17 campaigns between November 2004 and April 2007. The standard deviations obtained by least squares adjustment range from $\pm 9 \mathrm{~nm} / \mathrm{s}^{2}$ to $\pm 14 \mathrm{~nm} / \mathrm{s}^{2}$ for a gravity difference of one campaign, thus for gravity changes between two campaigns from $\pm 13 \mathrm{~nm} / \mathrm{s}^{2}$ to $\pm 20 \mathrm{~nm} / \mathrm{s}^{2}$. Between the points of the network, spatial gravity changes of up to $171 \mathrm{~nm} / \mathrm{s}^{2}\left(139 \mathrm{~nm} / \mathrm{s}^{2}\right.$ between two successive campaigns) could be proven significantly. They correlate with changes in the local hydrological situation. Particularly, a steep slope next to the observatory is identified as a gravimetrically significant hydrological compartment. The results obtained contribute to an improved reduction of the local hydrological signal in continuous gravity recordings and provide constraints to hydrological models.
\end{abstract}

Keywords. Earthquake swarms, gravimetric modelling, geodynamic modelling, finite element method

\footnotetext{
M. Naujoks · A. Weise · C. Kroner · T. Jahr

Department of Applied Geophysics, Institute of Geosciences,

Friedrich-Schiller-University Jena

Burgweg 11, D-07749 Jena, Germany

e-mail:m.naujoks@uni-jena.de
}

\section{Introduction}

Hydrological variations and their underlying processes have become an important focus of scientific interest in recent years, in particular as they represent a significant, broadband disturbance in geodynamic observations, especially in records of superconducting gravimeters. Effects in time-dependent gravity observations due to water level and soil moisture variations, precipitation events, and snow covering have been discussed for a while (e.g. Abe et al, 2006; Amalvict et al, 2004; Bonatz, 1967; Bower and Courtier, 1998; Crossley et al, 1998; Elstner, 1987; Elstner and Kautzleben, 1982; Harnisch and Harnisch, 1999; Imanishi, 2000; Kroner, 2001; Kroner et al, 2007; Lambert and Beaumont, 1977; Mäkinen and Tattari, 1988; Meurers et al, 2007; Peter et al, 1995; Sato et al, 2006; Virtanen, 2000; Zerbini et al, 2001). They range from a few $\mathrm{nm} / \mathrm{s}^{2}$ to some $10 \mathrm{~nm} / \mathrm{s}^{2}\left(10 \mathrm{~nm} / \mathrm{s}^{2}=1 \mu \mathrm{Gal}\right)$. Geodynamic signals, for instance from large-scale variations in the continental water balance, oscillations of the Earth's core or coseismic variations (Imanishi et al, 2004) are expected in a similar or even smaller order of magnitude. Hence, the investigation of geodynamic variations of a few $\mathrm{nm} / \mathrm{s}^{2}$ requires the elimination of this disturbing influence.

Recent studies regarding the reduction of hydrological effects in gravity observations (Boy and Hinderer, 2006; Harnisch and Harnisch, 2006; Hokkanen et al, 2007a,b; Imanishi et al, 2006; Kroner and Jahr, 2006; Van Camp et al, 2006) emphasise that, in particular, local hydrological fluctuations have a major effect on geodynamic observations. The close vicinity of the station $(<100 \mathrm{~m})$ may play a crucial role. From the comparison of local, regional, and global hydrological models with gravity observations, Virtanen et al (2006) concluded that for the station Metsähovi (Finland), approximately $2 / 3$ of the hydrological changes observed in gravity are caused by the local vicinity. Besides long-term, seasonal variations, short-term hydrological events like rainfalls cannot be neglected either (Meurers, 2006).

The local hydrological changes also need to be 
known and eliminated in order to combine recordings from superconducting gravimeters with GRACE satellite observations and for comparison with hydrological models (Neumeyer et al, 2006). In this context, the question emerges to what extent gravity observations can be used to parameterise and validate hydrological modelling. To obtain the data necessary for water balances like precipitation, water level, evaporation and soil moisture is partially difficult and generally only possible for a limited number of point observations (Hasan et al, 2006; Krause et al, 2005). The advantage of gravity data lies in the fact that they contain integral information on hydrological mass changes.

Besides large-scale GRACE satellite observations and ground monitoring at one location, small-scale spatial information is of interest to gain a broader knowledge about the hydrological processes acting in the subsoil and to deduce constraints for hydrological modelling on a local scale.

With the only absolute gravimeter available for spatially distributed outdoor measurements, the A10, developed by Micro-g LaCoste, an accuracy of $\pm 50 \mathrm{~nm} / \mathrm{s}^{2}$ (Liard and Gagnon, 2002) can be obtained, which is not sufficient to significantly detect hydrological variations of some $10 \mathrm{~nm} / \mathrm{s}^{2}$ in gravity. This leaves the option of deploying classical relative instruments, which also have the advantage of being easily available.

Using relative instruments, Jentzsch et al (2004) detected temporal gravity changes at the Mayon, Merapi, and Galeras volcanoes with a standard deviation of $\pm 100 \mathrm{~nm} / \mathrm{s}^{2}$ to $\pm 180 \mathrm{~nm} / \mathrm{s}^{2}$ [point distances up to $20 \mathrm{~km}$ and a gravity range of up to $7500 \mu \mathrm{m} / \mathrm{s}^{2}$ (750 mGal)]. Ergintav et al (2007) investigated temporal gravity changes due to postseismic deformations in the Marmara region, Turkey. They obtained accuracies of up to $\pm 100 \mathrm{~nm} / \mathrm{s}^{2}$ by deploying two relative instruments (point distances of several $10 \mathrm{~km}$ and a gravity range of some $100 \mu \mathrm{m} / \mathrm{s}^{2}$ ).

Regarding the Fennoscandian land uplift, relative measurements were carried out on a network with point distances of some $10 \mathrm{~km}$ and a gravity range of $5 \mu \mathrm{m} / \mathrm{s}^{2}$ with standard deviations of some $\pm 10 \mathrm{~nm} / \mathrm{s}^{2}$ (Ekman et al, 1987). From several campaigns on local networks it is known that standard deviations between $\pm 10 \mathrm{~nm} / \mathrm{s}^{2}$ and $\pm 20 \mathrm{~nm} / \mathrm{s}^{2}$ can be achieved for one difference using a collection of instruments (Vitushkin et al, 2002). Mäkinen and Tattari $(1988,1991)$ observed gravity variations related to hydrology with two relative gravimeters between two points with standard deviations of up to $\pm 13 \mathrm{~nm} / \mathrm{s}^{2}$ (point distance $2 \mathrm{~km}$, gravity range $\left.0.6 \mu \mathrm{m} / \mathrm{s}^{2}\right)$.

However, this study deals with the question whether or not it is possible to reach standard deviations of about $\pm 10 \mathrm{~nm} / \mathrm{s}^{2}$ on a local network, consisting of several points using relative gravimeters in repeated campaigns. If the answer is yes, spatially distributed gravity observations with relative instruments can lead to better, quantitative information on hydrological processes in the subsoil. Thus, on the one hand an improved reduction for local hydrological disturbances in continuous gravity observations may be developed. On the other hand, information can be gained from which additional constraints for hydrological models can be derived.

The investigations are carried out in the surroundings of the Geodynamic Observatory Moxa, Germany, at which a superconducting gravimeter is operated. The observatory lies in a narrow north-south striking valley with a small creek, the Silberleite (Fig. 1). The area is characterised by hilly topography and inhomogeneous subsoil. Water is stored as soil moisture, fissure water, ground water, in the canopy, and as snow in winter. The water masses are located above and below the level of the superconducting gravimeter and the aquifers are partially confined. The rain water partially drains off on the surface, partially percolates into the fissured rock and is partially stored in the soil layer (Hasan et al, 2006; Kroner et al, 2007). Gravity changes observed with the superconducting gravimeter turned out to be correlated with hydrological variations (Kroner, 2001). Effects related to water level and soil moisture variations were found.

The topography plays an important role in the local interaction between hydrology and gravity at Moxa. To the east, directly next to the observatory building, a steep slope rises in which interflow processes could be verified by experiments (Kroner and Jahr, 2006). Nevertheless, the significance of effects by time-delayed flow processes in the steep slope is not clear yet. The extension of the local gravimetrical significant area is also not known, and it needs to be determined which of the hydrological contributors dominate in which frequency range.

\section{Local gravity network and observations}

To detect hydrological variations in gravity within a defined area, the local gravity network MoxaNet was established in the surroundings of Moxa observatory. It consists of 12 observation points on massive concrete pillars in hydrologically different areas. Nine points were installed on already existing pillars in 


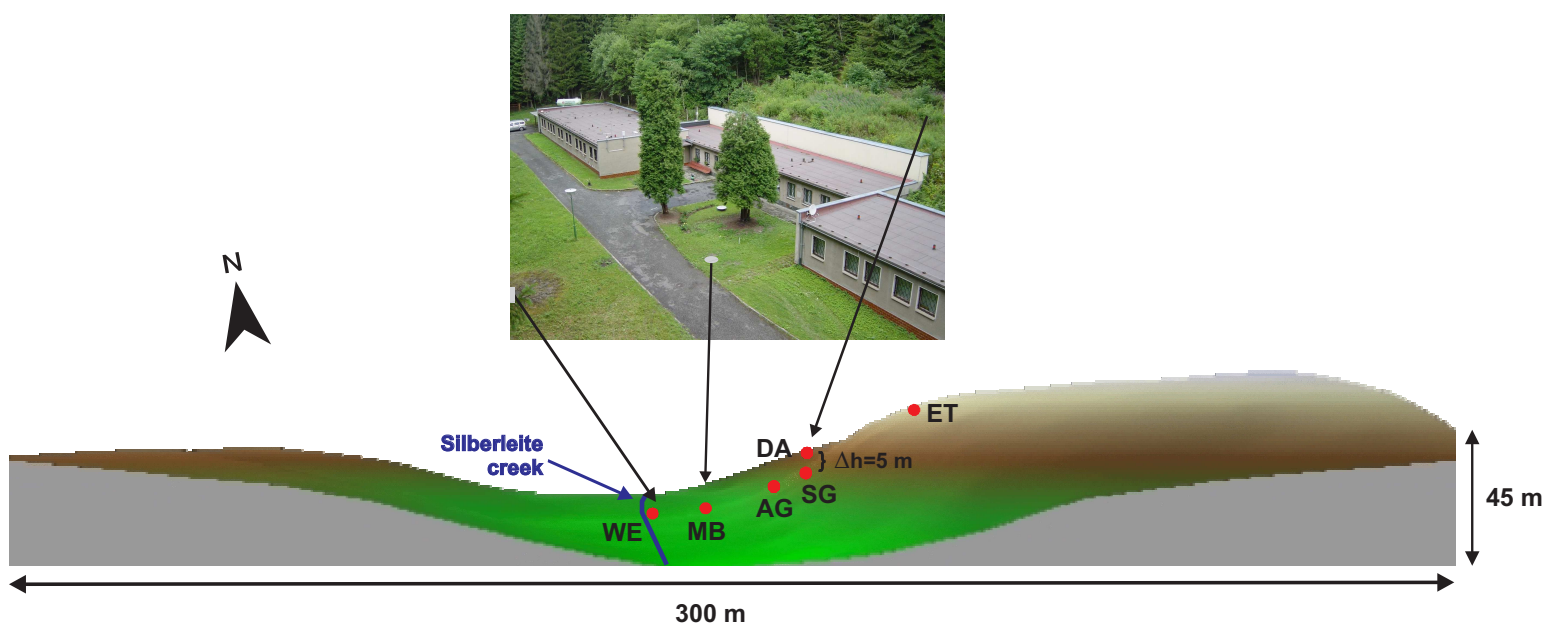

Figure 1: Location of the observation points in the local gravity network MoxaNet at the Geodynamic Observatory Moxa.

and around the observatory, three pillars were newly built with a diameter of $0.3 \mathrm{~m}$ and a foundation depth of $1 \mathrm{~m}$. Six points are located on an east-west profile running perpendicular to the topography in distances from a few up to $65 \mathrm{~m}$ (Fig. 1). The maximum height difference between these points is $25 \mathrm{~m}$, the maximum gravity difference is $44.2 \mu \mathrm{m} / \mathrm{s}^{2}$ (4.42 mGal).

One point $(E T)$ lies on the hill to the east of the observatory near the top of the steep slope, a second point $(D A)$ on the soil-covered roof of the observatory building. Another point $(S G)$ is next to the superconducting gravimeter in the observatory building at the base of the steep slope, so the data of the superconducting gravimeter can serve as a reference. Three more sites $(A G, M B, W E)$ are situated in the valley in increasing distances to the superconducting gravimeter. The point $A G$ lies inside the observatory building, the points $M B$ and $W E$ outside, the point $W E$ next to the Silberleite creek in an almost universally wet area.

The stability of the points was checked by repeated levelling. Significant height changes could not be found within the achieved accuracy of $\pm 1.5 \mathrm{~mm}$. Therefore, the stability of the points is better than $\pm 1.5 \mathrm{~mm}$.

For the measurements three to five LaCoste \& Romberg (LCR) relative gravimeters (G085, G858, D187, G662, and G896) were used, some of them chosen because of their very high accuracy known. All gravimeters are equipped with an electronic feedback system and the G662, G896, and D187 with electronic levels.

Measurements were carried out over a period of 26 months between November 2004 and April 2007 in 17 campaigns (lasting 2 or 3 days; Table 3) in a seasonal rhythm as well as at special hydrological events (snowmelt, intense rain, dryness; Fig. 3). For the measurements, the step method (Torge, 1989) was applied. The points $S G, A G$, and $M B$ were connected to a triangle; and each of the stations $W E, D A$, and ET was connected to two points of this triangle. Each observed gravity difference was measured at least five times with each gravimeter. Using four gravimeters, this results in 20 ties minimum between two points. Each observation is the arithmetic mean of three gravimeter readings at different spindle positions and with three different feedback readings, all close to zero (Sect. ). This results in a well configured network with approximately 200 observed gravity differences for each campaign.

\section{Calibration}

From long experience, the instruments used are known as high accuracy and robust instruments with low and stable drift rates (Atzbacher and Gerstenecker, 1993; Ergintav et al, 2007; Jentzsch et al, 2004; Kanngieser et al, 1983). Regarding the desired accuracy of $\pm 10 \mathrm{~nm} / \mathrm{s}^{2}$, the calibration, their stability, and systematics of the instruments are important. Systematic instrument-specific errors can only be minimised by using several gravimeters in parallel. Furthermore, uncertainties in the calibration can be reduced.

At the vertical gravimeter calibration line Hanover, Germany (Kanngieser et al, 1983; Timmen and Gitlein, 2004), periodic spindle calibration terms as well as linear and quadratic feedback cali- 
bration terms were determined for the gravimeters used. Linear calibration factors of the spindle were checked at the calibration line Hanover-Harz, which covers the gravity range of the MoxaNet. These calibration factors, shown in Table 1 and 2, were used additionally to the calibration given by the manufacturer.

Regarding the accuracy of $\pm 10 \mathrm{~nm} / \mathrm{s}^{2}$ striven for and the gravity range of the MoxaNet $\left(44.2 \mu \mathrm{m} / \mathrm{s}^{2}\right)$, linear calibration factors need to be stable within $1 \cdot 10^{-4}$. The stability of the linear calibration factors of the instruments used has been proven over decades in campaigns carried out by Atzbacher and Gerstenecker (1993); Ergintav et al (2007); Jentzsch et al (2004); Kanngieser et al (1983). Furthermore, the calibration values obtained on the Hanover-Harz line at different campaigns were compared with each other. Changes larger than $1 \cdot 10^{-4}$ could not be proved.

Periodic calibration terms arise due to the mechanical construction of the instruments. From long experience, these terms are known to be stable with time as long as the gravimeter is not modified. In contrast, the calibration factors of the feedback system

Table 1: Spindle calibration terms of the LCR gravimeters used.

\begin{tabular}{lcllr}
\hline Gravimeter & Linear term & Period $(\mathrm{CU})$ & $\mathrm{A}\left(\mathrm{nm} / \mathrm{s}^{2}\right)$ & $\phi\left(^{\circ}\right)$ \\
\hline \multirow{4}{*}{ LCR-G085 } & 1.001700 & 3.9400 & $13 \pm 7$ & $240 \pm 36$ \\
& \pm 0.000036 & 7.8800 & $70 \pm 7$ & $200 \pm 7$ \\
\hline \multirow{4}{*}{ LCR-G858 } & 1.000630 & 3.6700 & $30 \pm 13$ & $19 \pm 21$ \\
& \pm 0.000112 & 7.3300 & $26 \pm 10$ & $295 \pm 21$ \\
\hline \multirow{4}{*}{ LCR-D187 } & 0.995662 & 1.6250 & $72 \pm 5$ & $103 \pm 5$ \\
& \pm 0.000144 & 3.2500 & $48 \pm 8$ & $212 \pm 8$ \\
\hline \multirow{4}{*}{ LCR-G896 } & 1.000559 & 3.6700 & $43 \pm 21$ & $50 \pm 28$ \\
& \pm 0.000036 & 7.3300 & $151 \pm 19$ & $327 \pm 7$ \\
\hline \multirow{2}{*}{ LCR-G662 } & 1.000789 & 3.6700 & $64 \pm 10$ & $47 \pm 9$ \\
& \pm 0.000066 & 7.3300 & $31 \pm 11$ & $175 \pm 21$ \\
\hline
\end{tabular}

Table 2: Calibration terms of the feedback systems.

\begin{tabular}{llc}
\hline Gravimeter & Linear term & Quadratic term in $10^{-6}$ \\
\hline LCR-G085 & $1.05966 \pm 0.00030$ & $0.6570 \pm 0.0143$ \\
LCR-G858 & $1.06324 \pm 0.00044$ & $0.2310 \pm 0.0257$ \\
LCR-D187 & $1.11899 \pm 0.00019$ & $0.2624 \pm 0.0094$ \\
LCR-G896 & $1.04028 \pm 0.00036$ & $-0.4069 \pm 0.0156$ \\
LCR-G662 & $1.02682 \pm 0.00022$ & $-0.1985 \pm 0.0101$ \\
\hline
\end{tabular}

may change with time. Therefore, in the MoxaNet, all feedback readings were done with feedback values around zero $( \pm 20 \mathrm{mV})$. Thus, the influence of possible instabilities in the feedback calibration on the observations in the MoxaNet is negligible.

\section{Least squares adjustment}

The data were analysed by least squares (LS) adjustment using the GRAVNA program (Wenzel, 1993). The LS technique takes into account all observations to compute the unknowns (Großmann, 1969). This leads to consistent results and provides an insight into the scale and the distribution of the discrepancies among the observations. The residual equation for one gravity difference measured with one gravimeter is given by Kanngieser et al (1983) and Wolf (1997)

$$
v_{i, j}=\left(\bar{g}_{i}-\bar{g}_{j}\right)-\left(g_{i}-g_{j}\right)+D\left(t_{i}-t_{j}\right)
$$

with the adjusted gravity difference $\left(\bar{g}_{i}-\bar{g}_{j}\right)$ between the stations $i$ and $j$, the observed gravity difference $\left(g_{i}-g_{j}\right)$ between $i$ and $j$, a linear drift coefficient $D$ over the observation time $t_{i}-t_{j}$, and the residual $v_{i, j}$. The observed gravity difference $\left(g_{i}-g_{j}\right)$ is computed by converting the gravimeter readings $z_{i}$ and $z_{j}$ into gravity values $g_{i}$ and $g_{j}$ using firstly the calibration table provided by the manufacturer and correcting the influence of atmospheric pressure and earth tides.

Additionally, the calibration terms, determined at the gravimeter calibration system Hanover (Sect. ), are applied to the spindle readings. These are a linear calibration term $E_{1}\left(z_{i}-z_{j}\right)$ and the periodic calibration terms

$$
\sum_{n=1}^{p} X_{n}\left(\cos \frac{2 \pi z_{i}}{T_{n}}-\cos \frac{2 \pi z_{j}}{T_{n}}\right)
$$

and

$$
\sum_{n=1}^{p} Y_{n}\left(\sin \frac{2 \pi z_{i}}{T_{n}}-\sin \frac{2 \pi z_{j}}{T_{n}}\right)
$$

with the parameters $X_{n}=A_{n} \cdot \cos \phi_{n}, Y_{n}=A_{n} \cdot \sin \phi_{n}$, and $A_{n}=\sqrt{X_{n}^{2}+Y_{n}^{2}}$. In Eqs. (2) and (3), $n$ is the number of the periodic calibration term, $p$ the number of the periods to be corrected, $A$ the amplitude, $\phi$ the phase, and $T$ the period in counter units (CU) (Table 1). To the feedback readings of each gravimeter a linear and quadratic calibration term was applied (Table 2). Finally, the observed gravity differences of all gravimeters used enter the LS adjustment.

Because hydrological variations are expected at all observation points, no point could be fixed in 
the LS adjustment. Therefore, a free network adjustment was performed for each campaign. The unknowns of the system are the linear drift coefficients of the gravimeters and the gravity values of the stations from which the gravity differences are calculated. The results obtained are the adjusted gravity differences with their standard deviations for each campaign. For further interpretation the temporal changes of these gravity differences are considered.

\section{Accuracies and test measurements}

The standard deviation $\mathrm{m}_{0}$ for one single observation obtained in the combined adjustment of all gravimeters is between $\pm 54 \mathrm{~nm} / \mathrm{s}^{2}$ and $\pm 88 \mathrm{~nm} / \mathrm{s}^{2}$ (Table 3 ). Besides the $m_{0}$ of the combined adjustment, the standard deviation $\mathrm{m}_{0}$ of a single observation with each gravimeter used is also shown in Table 3 for each campaign. Statistically insignificant values (outlier criterium: $>3 \cdot \mathrm{m}_{0}$ ) were removed from the data.

At the point $S G$ time-dependent hydrologically caused gravity variations of a few $10 \mathrm{~nm} / \mathrm{s}^{2}$ could be detected in the data of the superconducting gravimeter (Kroner, 2001). In the first four campaigns of the repeated measurements the standard deviation $\mathrm{m}_{\Delta g}$ of an adjusted gravity difference is between $\pm 12 \mathrm{~nm} / \mathrm{s}^{2}$ and $\pm 31 \mathrm{~nm} / \mathrm{s}^{2}$. Thus, the standard deviation $\mathrm{m}_{g}$ of a gravity value at the stations is between $\pm 8 \mathrm{~nm} / \mathrm{s}^{2}$ and $\pm 22 \mathrm{~nm} / \mathrm{s}^{2}$. These standard deviations obtained for the first four campaigns of the repeated measurements are too large to detect hydrological variations of a few $10 \mathrm{~nm} / \mathrm{s}^{2}$ significantly. To increase the accuracy, extensive tests were carried out:

- The comparison of the standard deviations $\mathrm{m}_{0}$ of one single observation for the different gravimeters showes that the gravimeters LCRG085, LCR-G858, and LCR-D187 are highprecision instruments (Table 3). The LCRG662 also has a fairly small $\mathrm{m}_{0}$, but was not always available when needed. The LCR-G896 is less suitable for high-precision repeated measurements. Therefore, in the following campaigns mainly the instruments LCR-G085, LCR-G858, and LCR-D187 were used.

- A simple model was used to get a first rough estimate of the hydrological effects to be expected at the various observation points. It includes a soil layer (thickness $1.5 \mathrm{~m}$, porosity $25 \%$ ), a fissured rock layer (thickness $15 \mathrm{~m}$, porosity $2 \%$ ), and the topography in the observatory surroundings. A change from a very wet to a dry situation was considered. The vol- umetric soil water content was assumed to decrease by $5 \%$ for the soil layer, and $2 \%$ for the fissured rock layer. From the results a gravity increase of $38 \mathrm{~nm} / \mathrm{s}^{2}$ for the point $S G$, and a gravity decrease of $22 \mathrm{~nm} / \mathrm{s}^{2}$ for the point $M B$ and $89 \mathrm{~nm} / \mathrm{s}^{2}$ for the point $E T$ is derived. Therefore, the difference $S G$-ET increases by $127 \mathrm{~nm} / \mathrm{s}^{2}$, the difference $M B-E T$ by $67 \mathrm{~nm} / \mathrm{s}^{2}$, and the difference $M B-S G$ decreases by $60 \mathrm{~nm} / \mathrm{s}^{2}$.

- From the estimate can be inferred that the largest effects ought occur between points in the valley and the higher located points due to their different hydrological situation. Thus, the measurements were focussed on the six points on the profile running perpendicular to the topography (Fig. 1). In addition, some hydrological events like snowmelt or heavy rain last only a few days or less. To catch these events in the repeated campaigns the gravity network needs to be covered within a few days; the observation campaign needs to be completed before the hydrological situation changes. The tests showed that the gravity differences between the six observation points on the profile can be covered within 2 days.

- In the first four campaigns different network configurations were tested in order to achieve the best results regarding accuracy and effective measuring regime. In these campaigns measurements were carried out not always at the points $W E$ and $D A$.

- The gravity differences from the points within the valley to the point ET at the steep slope are the largest in the MoxaNet. Furthermore, the transportation of the instrument to the point ET takes approximately $15 \mathrm{~min}$, between the points in the valley less than $5 \mathrm{~min}$. Therefore, these differences to the point ET are affected by the largest errors. To counter this, the number $n$ of observed gravity differences $\left(g_{i}-g_{j}\right)$ from two points in the valley to the point $E T$ was increased from 10 to 14 .

- In the first four campaigns occasionally a smaller number of gravity differences than described in Sect. was observed. This partially could have caused the lower accuracies in this start period of the measurements. The observation scheme described in Sect. turned out to be best suited; it was used in the campagins 5-17. 
Table 3: Standard deviations for the LCR gravimeters used derived from LS adjustment for each campaign.

\begin{tabular}{|c|c|c|c|c|c|c|c|c|c|}
\hline \multirow{3}{*}{$\begin{array}{l}\text { Campaign } \\
\text { No. }\end{array}$} & \multirow{3}{*}{$\begin{array}{l}\text { Date } \\
\mathrm{yy} / \mathrm{mm} / \mathrm{dd}\end{array}$} & \multicolumn{8}{|c|}{ LCR gravimeter } \\
\hline & & \multirow{2}{*}{$\begin{array}{l}\text { G085 } \\
\mathrm{m}_{0}\end{array}$} & \multirow{2}{*}{$\begin{array}{l}\text { G858 } \\
\mathrm{m}_{0}\end{array}$} & \multirow{2}{*}{$\begin{array}{l}\mathrm{D} 187 \\
\mathrm{~m}_{0}\end{array}$} & \multirow{2}{*}{$\begin{array}{l}\text { G662 } \\
\mathrm{m}_{0}\end{array}$} & \multirow{2}{*}{$\begin{array}{l}\text { G896 } \\
m_{0}\end{array}$} & \multicolumn{3}{|c|}{ Combined } \\
\hline & & & & & & & $\mathrm{m}_{0}$ & $\mathrm{~m}_{g}$ & $\mathrm{~m}_{\Delta g}$ \\
\hline 1 & 2004/11/17-29 & 49 & 72 & 97 & 118 & 141 & 68 & 13 & 19 \\
\hline 2 & 2004/12/09 & - & 77 & - & 98 & 91 & 87 & 22 & 31 \\
\hline 3 & $2004 / 12 / 16$ & 37 & - & - & 109 & 117 & 88 & 14 & 20 \\
\hline 4 & 2005/01/06 & 22 & - & - & 96 & 110 & 64 & 8 & 12 \\
\hline 5 & 2005/03/18-20 & 49 & 55 & 47 & - & 131 & 73 & 8 & 12 \\
\hline 6 & 2005/07/14-15 & 55 & 62 & 64 & - & 70 & 61 & 7 & 10 \\
\hline 7 & $2005 / 08 / 24-25$ & 53 & 53 & 73 & 73 & - & 63 & 7 & 10 \\
\hline 8 & 2005/09/28-29 & 42 & 61 & 43 & 73 & - & 58 & 6 & 9 \\
\hline 9 & 2006/02/17-19 & 34 & 87 & 46 & 85 & - & 70 & 6 & 9 \\
\hline 10 & 2006/04/05-06 & 57 & 70 & 65 & 65 & - & 67 & 8 & 12 \\
\hline 11 & 2006/05/16-17 & 37 & 66 & 47 & - & 85 & 54 & 9 & 13 \\
\hline 12 & 2006/08/14-16 & 33 & 95 & 74 & - & - & 80 & 9 & 13 \\
\hline 13 & 2006/09/11-12 & 30 & 73 & 77 & - & 99 & 75 & 7 & 10 \\
\hline 14 & 2006/11/10-11 & 85 & 90 & 74 & - & - & 84 & 10 & 14 \\
\hline 15 & 2007/01/12-16 & 46 & 76 & 69 & - & - & 69 & 8 & 12 \\
\hline 16 & 2007/02/26-27 & 50 & 83 & 73 & - & - & 76 & 9 & 13 \\
\hline 17 & $2007 / 04 / 23-24$ & 40 & 80 & 80 & - & - & 66 & 9 & 13 \\
\hline
\end{tabular}

$\left(\mathrm{m}_{0}\right.$, standard deviation of one single observed gravity difference $\left(\mathrm{nm} / \mathrm{s}^{2}\right) ; \mathrm{m}_{g}$, standard deviation of the gravity values at the stations $\left(\mathrm{nm} / \mathrm{s}^{2}\right) ; \mathrm{m}_{\Delta g}$, standard deviation of an adjusted gravity difference $\left(\mathrm{nm} / \mathrm{s}^{2}\right)$; campaigns 1-4: test phase)

- Highest accuracies are obtained if always the same well-versed persons observe the gravity differences, each person always with the same gravimeter.

- The LS adjustment was done with and without consideration of periodic spindle calibration terms. The results with higher accuracy are obtained when periodic terms are taken into account.

Considering these findings, in the subsequent campaigns the standard deviation $\mathrm{m}_{\Delta g}$ of an adjusted gravity difference ranges between $\pm 9 \mathrm{~nm} / \mathrm{s}^{2}$ and $\pm 14 \mathrm{~nm} / \mathrm{s}^{2}$. Thus, the standard deviation $\mathrm{m}_{g}$ of a gravity value at the stations is between $\pm 6 \mathrm{~nm} / \mathrm{s}^{2}$ and $\pm 10 \mathrm{~nm} / \mathrm{s}^{2}$ (Table 3). It is within the order of magnitude of the time-dependent hydrologically caused gravity variations observed near the point $S G$ by the superconducting gravimeter.

\section{Results}

The scattering of the observed, drift-reduced gravity differences $\left(g_{i}-g_{j}\right)$ (Eq. 1) and the temporal changes between the campaigns are shown in Fig. 2 for each LCR gravimeter used, and for all gravity differences between the points $M B, A G, S G$, and $E T$. In the first four campaigns the scattering is larger than in the following campaigns due to changes in the network design (Sect. ). The results obtained with the different gravimeters fit together well. This is one prerequisite to achieve reliable results in the combined adjustment.

Significant temporal changes cannot be proven in the individual differences, but tendencies can be identified: Between the campaigns 5 and 6 , as well as 9 and 10 an increase in the differences $M B-E T$ and $A G-E T$ is observed with all gravimeters (Fig. 2 a, b). This increase also can be identified between the campaigns 9 and 10 in the difference $S G-E T$ (Fig. 2 c), at 


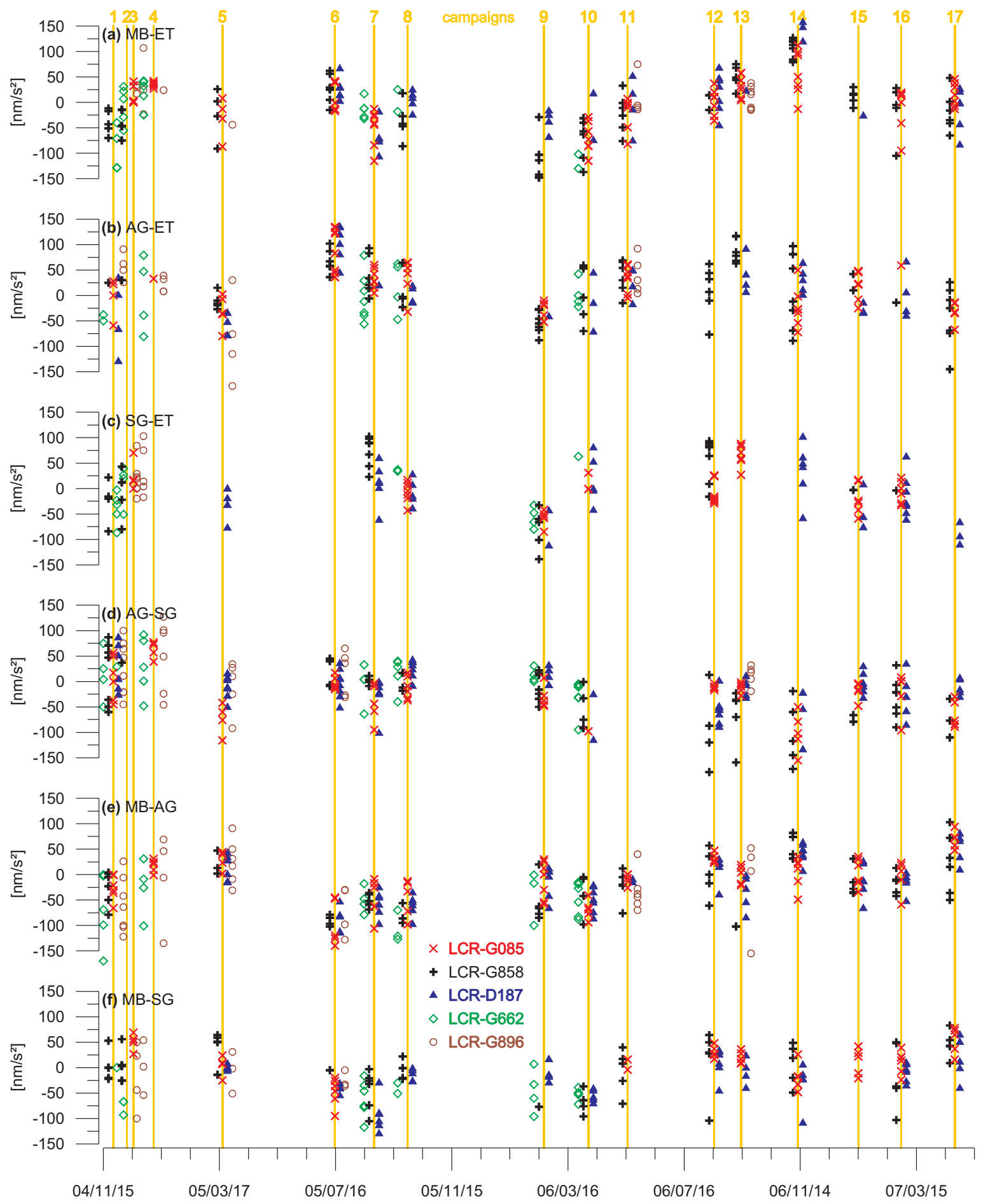

Figure 2: Scattering of the drift-reduced gravity differences $\left(g_{i}-g_{j}\right)$ and temporal changes between the campaigns for each LCR gravimeter used; gravity difference between the points a $M B-E T$, b $A G-E T$, c $S G-E T$, d $A G-S G$, e $M B-A G$, and $\mathbf{f} M B-S G$ (cf. Table 3 and Fig. 1); campaigns 1-4: test phase. 


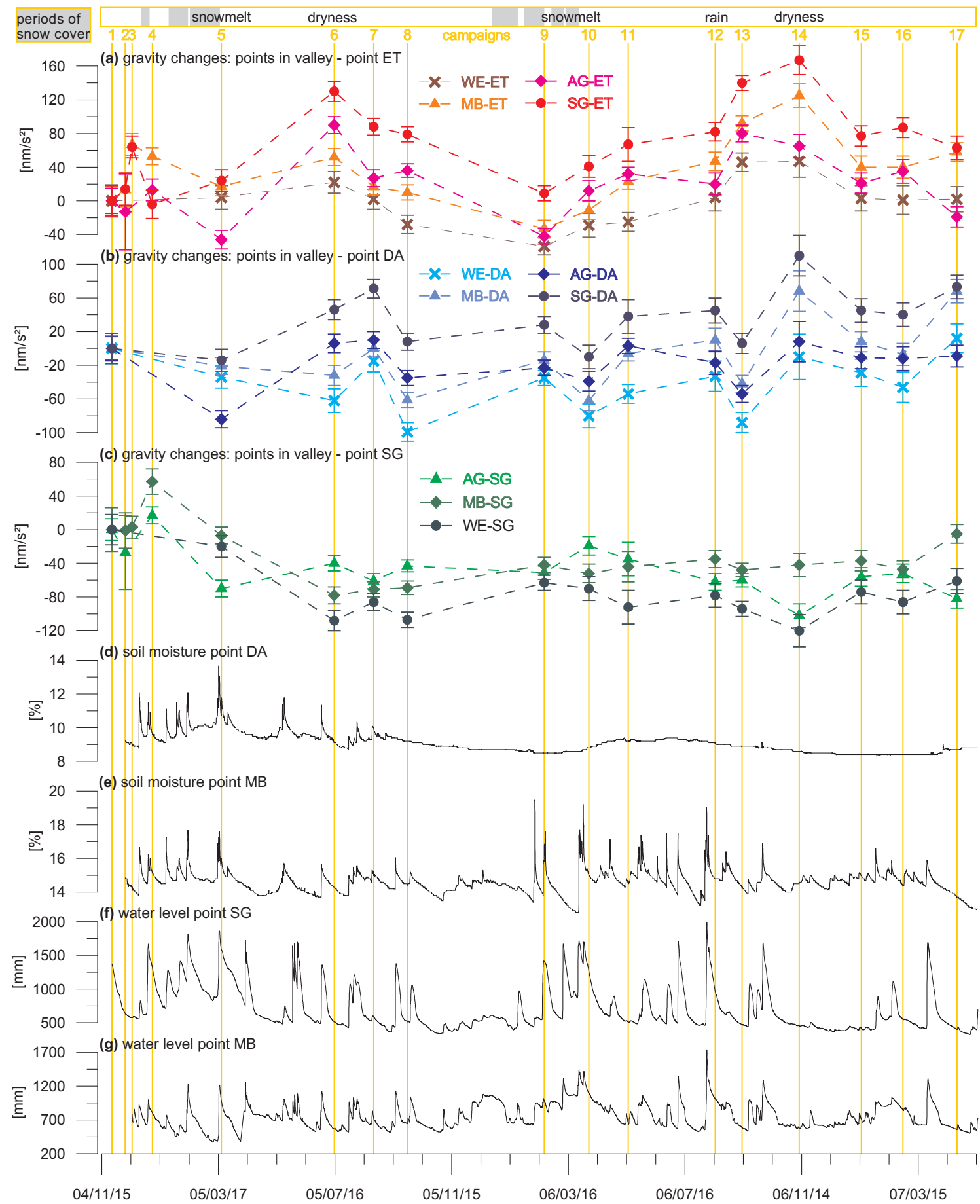

Figure 3: Temporal changes in the gravity differences with standard deviation and some hydrological parameters at the observation points: a gravity changes between different points in the valley in different distance to the steep slope and point ET on the hill (cf. Fig. 1), b gravity changes between different points in the valley in different distance to the steep slope and point $D A$ on the roof of the observatory, $\mathbf{c}$ gravity changes between the points in the valley and point $S G, \mathbf{d}$ soil moisture variations at point $D A$ at $1 \mathrm{~m}$ depth, e soil moisture variations at point $M B$ at $1 \mathrm{~m}$ depth, $\mathbf{f}$ mostly pore water pressure induced water level variations at point $S G, \mathbf{g}$ water level variations at point $M B$. 
campaign 6 this difference was not observed.

Regarding the differences including the point ET (Fig. $2 \mathrm{a}-\mathrm{c}$ ), the scattering is larger than for the differences between stations within the Silberleite valley (Fig. $2 \mathrm{~d}-\mathrm{f}$ ). This is due to the large gravity difference and the long transportation time to the point $E T$ (Sect. ).

Despite the small gravity differences between the points within the valley, temporal changes can be identified likewise, partially with opposite tendencies. For instance, between the campaigns 5 and 6 a decrease in the differences $M B-A G$ and $M B-S G$ is observed by all gravimeters used (Fig. 2 e,f), whereas the difference $A G-S G$ increases (Fig. 2 d). However, these tendencies become more evident regarding the adjusted gravity differences.

In Fig. 3 the results of the repeated observations are shown. Besides the temporal changes in the adjusted gravity differences with standard deviation (Fig. $3 \mathrm{a}-\mathrm{c}$ ), variations of some hydrological parameters are also given (Fig. $3 \mathrm{~d}-\mathrm{g}$ ).

The standard deviation obtained for one adjusted gravity difference of one campaign ranges from $\pm 9 \mathrm{~nm} / \mathrm{s}^{2}$ to $\pm 14 \mathrm{~nm} / \mathrm{s}^{2}$, and for gravity changes between two campaigns from $\pm 13 \mathrm{~nm} / \mathrm{s}^{2}$ to $\pm 20 \mathrm{~nm} / \mathrm{s}^{2}$ (Table 3, Fig. $3 \mathrm{a}-\mathrm{c}$ ). Thus, gravity changes obtained larger then the double standard deviation, which ranges from $\pm 26 \mathrm{~nm} / \mathrm{s}^{2}$ to $\pm 40 \mathrm{~nm} / \mathrm{s}^{2}$, are significant.

Maximum changes of $171 \mathrm{~nm} / \mathrm{s}^{2}\left(139 \mathrm{~nm} / \mathrm{s}^{2}\right.$ between the two successive campaigns 5 and 6) are observed in the gravity differences between the points within the Silberleite valley and the point $E T$ near the top of the steep slope (Fig. $3 \mathrm{a}$ ). These changes are maximum for the differences containing the points $S G$ and $A G$, both situated in the observatory building, and decrease for the differences from the points in the valley with increasing distance from the slope: For the difference from the point $S G$ which is closest to the steep slope they reach $171 \mathrm{~nm} / \mathrm{s}^{2}$, for the differences from the point $A G$ in $8 \mathrm{~m}$ distance to the slope $136 \mathrm{~nm} / \mathrm{s}^{2}$, and for the difference from the point $W E$ outside the observatory only $101 \mathrm{~nm} / \mathrm{s}^{2}$. A similar result is found for the gravity differences between the points within the valley and the point $D A$ on the observatory roof (Fig. 3 b). These differences also show large variations of up to $130 \mathrm{~nm} / \mathrm{s}^{2}$ which mostly decrease for the differences from the points in the valley with increasing distance from the slope.

These results indicate that the hill slope plays a crucial role in the changes of the gravity differences. The stronger the changes in the topography between two observation points, the larger are the gravity changes. This is also recognisable in the gravity differences between the observation points within the valley (Fig. $3 \mathrm{c}$ ). For these differences, no significant changes are detectable, but trends can be observed. The unusual high values of these differences in campaign 4 may be due to changes in the network design at campaign 4 and the fact that the high-precision instruments G858 and D187 were missing in this campaign (Sect. , Table 3). However, in the following campaigns the changes in the difference $A G-S G$ show almost always an opposite trend to the differences $M B-S G$ and $W E-S G$, which can be explained by the particular situation of the points $A G$ and $S G$, both inside the observatory building. This trend is also visible in the gravity changes between the points within the valley and the point $E T$ or $D A$ (Fig. $3 \mathrm{a}, \mathrm{b}$ ); in particular between campaigns 5 and 6 , as well as 16 and 17.

As an indication of the respective hydrological situation, water level variations at the points $M B$ and $S G$ as well as soil moisture variations at the points $M B$ and $D A$ are also shown in Fig. 3. Water level variations are monitored using the hydrostatic pressure sensor water pilot FMX 167 by Endress+Hauser. Soil moisture variations are observed using TrimeEZ TDR probes. The soil moisture data show variations of up to $6 \%$ (Fig. $3 \mathrm{~d}$, e), the water level observations of up to $1,500 \mathrm{~mm}$ (Fig. $3 \mathrm{f}$, g), with peaks after rain events or at snowmelts.

Comparing the obtained temporal changes in the gravity differences with variations of the hydrological parameters observed, essential results can be derived:

During wet conditions, recognisable from high water level and high soil moisture (peaks in Fig. $3 \mathrm{~d}-$ g) as well as the appearance of water in usually dry areas, the gravity differences between various points in the Silberleite valley in different distance to the steep slope and the point ET near the top of the steep slope east of the observatory are smaller, during dry conditions significantly larger (Fig. 3 a). Between snowmelt and dry summer in the years 2005 and 2006 (between campaigns 5 and 6, as well as 9 and 11) the maximum changes of up to $139 \mathrm{~nm} / \mathrm{s}^{2}$ could be observed. During snowmelt (wet condition) the gravity differences are some ten $\mathrm{nm} / \mathrm{s}^{2}$ smaller than in the dry summer. A long lasting snow cover between campaigns 8 and 9 caused a rather low water level (Fig. $3 \mathrm{f}, \mathrm{g}$ ) and made gravity measurements impossible.

The different hydrological effects (e.g. soil moisture, ground water, fissure water) which are influencing gravity in the different hydrological com- 
partments partially compensate in the middle of the valley (points $W E$ and $M B$ ), but increase at the steep slope (points $S G$ and $A G$ ). Thus, hydrologically caused gravity changes also appear in the differences $A G-S G, M B-S G$, and $W E-S G$ in the Silberleite valley as shown in Fig. 3 c. The deviations in the changes of the gravity differences between the points within the valley and the opposite trend described above may be explained by the respective position of the observation points and their local hydrological situation. In particular, the points $S G$ and $A G$ are strongly influenced by hydrological variations in the hill.

Very local particularities have an essential influence on the gravity differences and result in a very complex image of the temporal changes. The observed gravity changes are significantly influenced by the hydrological processes acting in the steep slope between the point on the hill and the points in the valley. They can be explained by varying water masses within the slope. This influence is larger than firstly expected as the changes in the gravity differences show. From observations with the superconducting gravimeter, the hydrological influence of the hill slope can only be deduced indirectly. This effect becomes only "visible" because of the almost nonexistence of seasonal variations in the data related to changes in the continental water storage found at other stations. At Moxa the hydrological influence from the hill slope practically compensates this signal.

The changes in the gravity differences between different points in the valley and the point $D A$ on the observatory roof (Fig. 3 b) also depend on the hydrological situation. The differences $S G-D A$ and $A G-D A$ (e.g. between campaigns 5 and 6 ) show a similar behaviour as well as the differences $M B-D A$ and $W E$ $D A$. The roof of the observatory was covered with waterproof film in autumn 2005. This reduced the soil moisture variations on the roof (Fig. $3 \mathrm{~d}$ ). However, the observed gravity changes do not decrease after the sealing of the roof. This shows that soil moisture variations on the roof have only a minor impact on the gravity differences. Other hydrological processes in the surrounding, in particular water storage and flow processes in the hill slope, have a larger impact. Thus, the sealing of the roof had only a minor effect on the gravity differences. In the data of the superconducting gravimeter the sealing effect can be observed. It would probably be possible to measure it in the gravity differences too, if they could be recorded continuously.

As described above, the observed gravity changes are associated with the hydrological situation at the respective points as indicated by soil moisture and water level measurements. However, the hydrological situation at Moxa observatory is rather complicated and a direct correlation between changes in the gravity differences and soil moisture or water level variations is not always fully observable. For instance, the changes between campaigns 12 and 15 (Fig. $3 \mathrm{a}-\mathrm{c}$ ) do not clearly reflect the observed soil moisture or water level variations at the points $S G$, $M B$, or $D A$. But the soil moisture and water level observations describe only the particular situation at the point of the measurement. They do not need to be valid in some distance to these points. In contrast, the gravimeter detects the integral hydrological signal. Thus, a direct correlation between hydrological time series and the gravity differences is not to be expected. The hydrological data shown rather serve as an indicator for changes in the hydrological situation.

\section{Conclusion and outlook}

The objective of this study was to investigate the possibility to detect spatial hydrological variations of a few $10 \mathrm{~nm} / \mathrm{s}^{2}$ using relative gravimeters and to identify, understand and quantify hydrological processes by their influence on gravity. For this purpose, a local gravity network was established and spatially distributed measurements were carried out using LCR relative gravimeters in a seasonal rhythm as well as at special hydrological events like snowmelt or dryness. From the results of these observations, the following conclusions can be drawn:

- Within a local gravity network with point distances of several $10 \mathrm{~m}$, it is basically possible to achieve standard deviations between $\pm 9 \mathrm{~nm} / \mathrm{s}^{2}$ and $\pm 14 \mathrm{~nm} / \mathrm{s}^{2}$ for one adjusted gravity difference of one campaign by repeated measurements using LCR relative instruments.

- Changes in the gravity differences turned out to be associated with hydrological processes. Hydrological mass shifts between points in different hydrological areas of up to $171 \mathrm{~nm} / \mathrm{s}^{2}$ (139 $\mathrm{nm} / \mathrm{s}^{2}$ between two successive campaigns), for instance caused by hilly topography, could be proven significantly.

- A previously unknown gravimetrically significant hydrological storage in the hill to the east of Moxa observatory could be localised by the spatially distributed measurements.

Additionally, it can be derived from the results that for other high-precision measurements, including the calibration of relative gravimeters on calibra- 
tion lines, effects due to hydrology may have a nonnegligible influence. They also may strongly depend on very local changes in the topography. Depending on the gravity range covered by the calibration line in particular the determination of periodic calibration terms may be influenced and the accuracy may be reduced. In outdoor gravimeter calibration lines in hilly topography effects of some $\pm 10 \mathrm{~nm} / \mathrm{s}^{2}$ may occur. Point locations with a minimum hydrological influence should be chosen to minimise this effect.

As this study shows, the hydrological situation at Moxa observatory and the dependency between gravity and hydrology is rather complicated. To fully understand the observed gravity variations, to improve the reduction of the data of the superconducting gravimeter, and to provide constraints to hydrological models, gravimetric 3D modelling of the observatory surroundings will be carried out. Using the software IGMAS (Götze and Lahmeyer, 1988) it will be based on a geological and a soil mapping. Hydrological observations as well as a small-scale hydrological catchment model provide the input for the timedependent gravimetric modelling. Together with the gravity observations the results of the modelling can be interpreted quantitatively and the dependency between gravity and hydrology can be studied in a comprehensive geological and hydrological context.

\section{Acknowledgements}

Without the contribution of a number of persons, the extensive fieldwork would not have been possible. We thank Raphael Dlugosch, Anne Hegewald, Katrin Heinzig, Holger Hartmann, Gerhard Jentzsch, Romy Schmidt, Stefanie Zeumann, and Albrecht Ziegert from the Friedrich-Schiller-University Jena for their help. From discussions with Peter Krause, also from the University Jena, valuable information of the local hydrology around Moxa observatory was derived. The work of Wernfrid Kühnel and Matthias Meininger from Moxa observatory in establishing and maintaining the hydrological observation network is gratefully acknowledged. We are indepted to the Institute of Geodesy and Geoinformationtechnology of the Technical University Berlin and the Leibniz Institute for Applied Geosciences for lending us their instruments. We thank Bruno Meurers, two anonymous reviewers, and the responsible editor He-Ping Sun for constructive comments and valuable suggestions which improved the paper considerably. This research is supported by the German Research Foundation (DFG) by grants KR 1906/6-1-2 and KR 1906/6-3.

\section{References}

Abe M, Takemoto S, Fukuda Y, Higashi T, Imanishi Y, Iwano S, Ogasawara S, Kobayashi Y, Takiguchi H, Dwipa S, Kusuma DS (2006) Hydrological effects on the superconducting gravimeter observation in Bandung. J Geodyn 41(1-3):288-295, doi:10.1016/j.jog.2005.08.030

Amalvict A, Hinderer J, Mäkinen J, Rosat S, Rogister Y (2004) Long-term and seasonal gravity changes at the Strasbourg station and their relation to crustal deformation and hydrology. J Geodyn 38(3-5):343-353, doi:10.1016/j.jog.2004.07.010

Atzbacher K, Gerstenecker C (1993) Secular gravity variations: recent crustal movements or scale factor changes. J Geodyn 18(1-4):107-121, doi:10.1016/0264-3707(93)90033-3

Bonatz M (1967) Der Gravitationseinfluß der Bodenfeuchte. Zeitschrift für Vermessungswesen 92:135-139

Bower D, Courtier N (1998) Precipitation effects on gravity measurements at the Canadian absolute gravity site. Phys Earth Planet Int 106(3-4):353369, doi:10.1016/S0031-9201(97)00101-5

Boy JP, Hinderer J (2006) Study of the seasonal gravity signal in superconducting gravimeter data. J Geodyn 41(1-3):227-233, doi:10.1016/j.jog.2005.08.035

Crossley D, Xu S, van Dam T (1998) Comprehensive analysis of 2 years of $\mathrm{SG}$ data from table mountain, Colorado. In: Ducarme B, Pâquet P (eds) Proceedings of the 13th International Symposium on Earth Tides, Observatoire Royal de Belgique, Brussels, Schweizerbart'sche Verlagsbuchhandlung, pp 659-668

Ekman M, Mäkinen J, Midtsundstad A, Remmer O (1987) Gravity change and land uplift in Fennoscandia 1966 - 1984. J Geodesy 61(1):6064, doi:10.1007/BF02520415

Elstner C (1987) On common tendencies in repeated absolute and relative gravity measurements in the central part of the GDR. Gerl Beitr z Geophysik 96:197-205

Elstner C, Kautzleben H (1982) Results of annual gravity measurements along a W-E profile inside the GDR for the period 1970-1980. Proc Gen Meeting of the IAG, Tokyo pp 341-348 
Ergintav S, Doğan U, Gerstenecker C, Çakmak R, Belgen A, Demirel H, Aydin C, Reilinger R (2007) A snapshot (2003-2005) of the 3D postseismic deformation for the 1999, $M_{w}=7.4$ İzmit earthquake in the Marmara Region, Turkey, by first results of joint gravity and GPS monitoring. J Geodyn 44:1-18, doi:10.1016/j.jog.2006.12.005

Götze HJ, Lahmeyer B (1988) Application of three-dimensional interactive modelling in gravity and magnetics. Geophysics 53(8):1096-1108, doi:10.1190/1.1442546

Großmann W (1969) Grundzüge der Ausgleichsrechnung, 3rd edn. Springer, Berlin, Heidelberg, New York

Harnisch G, Harnisch M (2006) Hydrological influences in long term gravimeter data series. J Geodyn 41(1-3):276-287, doi:10.1016/j.jog.2005.08.018

Harnisch M, Harnisch G (1999) Hydrological influences in the registrations of superconducting gravimeters. Bulletin d'Information des Marées Terrestres 131:10 161-10 170

Hasan S, Troch P, Boll J, Kroner C (2006) Modeling of the hydrological effect on local gravity at Moxa, Germany. J Hydrometeor 7(3):346-354, doi:10.1175/JHM488.1

Hokkanen T, Korhonen K, Virtanen H, Laine EL (2007a) Effects of the fracture water of bedrock on superconducting gravimeter data. Near Surface Geophysics 5:133-140

Hokkanen T, Virtanen H, Pirttivaara M (2007b) On hydrogeological noise in superconducting gravimeter data. Near Surface Geophysics 5:125-132

Imanishi Y (2000) Present status of SG T011 at Matsushiro, Japan. Cahiers du Centre Européen de Géodynamique et de Séismologie 17:97-102

Imanishi Y, Sato T, Higashi T, Sun W, Okubo S (2004) A Network of Superconducting Gravimeters Detects Submicrogal Coseismic Gravity Changes. Science 306:476-478, doi:10.1126/science. 1101875

Imanishi Y, Kokubo K, Tatehata H (2006) Effect of underground water on gravity observation at Matsushiro, Japan. J Geodyn 41:221-226, doi:10.1016/j.jog.2005.08.031
Jentzsch G, Weise A, Rey C, Gerstenecker C (2004) Gravity changes and internal processes: Some results obtained from observations at three volcanoes. Pure Appl Geophys 161(7):1415-1431, doi:10.1007/s00024-004-2512-7

Kanngieser E, Kummer K, Torge W, Wenzel HG (1983) Das Gravimeter Eichsystem Hannover. Wiss Arb der Fachrichtung Vermessungswesen der Universität Hannover 120

Krause P, Fink M, Kroner C, Sauter M, Scholten T (2005) Hydrological processes in a small headwater catchment and their impact on gravimetric measurements. Proc Headwater 2005, Bergen

Kroner C (2001) Hydrological effects on gravity data of the Geodynamic Observatory Moxa. J Geod Soc Japan 47(1):353-358

Kroner C, Jahr T (2006) Hydrological experiments around the superconducting gravimeter at Moxa Observatory. J Geodyn 41(1-3):268-275, doi:10.1016/j.jog.2005.08.012

Kroner C, Jahr T, Naujoks M, Weise A (2007) Hydrological signals in gravity - foe or friend? In: Rizos C, Tregoning P (eds) Dynamic Planet - Monitoring and Understanding a Dynamic Planet with Geodetic and Oceanographic Tools, IAG Symposia Series. Springer, vol 130, pp 504-510

Lambert A, Beaumont C (1977) Nano variations in gravity due to seasonal groundwater movements; implications for the gravitational detection of tectonic movements. J Geophys Res 82:297-305

Liard J, Gagnon C (2002) The new A-10 absolute gravimeter at the 2001 International Comparison of Absolute Gravimeters. Metrologia 39(5):477483, doi:10.1088/0026-1394/39/5/8

Mäkinen J, Tattari S (1988) Soil moisture and groundwater: Two sources of gravity variations. Bulletin d'Information des Marées Terrestres 63:103-110

Mäkinen J, Tattari S (1991) The influence of variation in subsurface water storage on observed gravity. Proc 11th Int Symp Earth Tides, 1989, Schweizerbart'sche Verlagsbuchhandlung, Stuttgart, pp 457-471

Meurers B (2006) Long and short term hydrological effects on gravity in Vienna. Bulletin d'Information des Marées Terrestres 142:11,34311,352 
Meurers B, Van Camp M, Petermans T (2007) Correcting superconducting gravity time-series using rainfall modelling at the Vienna and Membach station and application to Earth tide analysis. J Geodesy 81(11):703-712, doi:10.1007/s00190007-0137-1

Neumeyer J, Barthelmes F, Dierks O, Flechtner F, Harnisch M, Harnisch G, Hinderer J, Imanishi Y, Kroner C, Meurers B, Petrovic S, Reigber C, Schmidt R, Schwintzer P, Sun HP, Virtanen $\mathrm{H}$ (2006) Combination of temporal gravity variations resulting from superconducting gravimeter $(\mathrm{SG})$ recordings, GRACE satellite observations and global hydrology models. J Geodesy 79(1011):573-585, doi:10.1007/s00190-005-0014-8

Peter G, Klopping F, Berstis K (1995) Observing and modeling gravity changes caused by soil moisture and groundwater table variations with superconducting gravimeters in Richmond, Florida, U.S.A. Cahiers du Centre Européen de Géodynamique et de Séismologie 11:147-159

Sato T, Boy JP, Tamura Y, Matsumoto K, Asari K, Plag HP, Francis O (2006) Gravity tide and seasonal gravity variation at Ny-Ålesund, Svalbard in Arctic. J Geodyn 41(1-3):234-241, doi:10.1016/j.jog.2005.08.016

Timmen L, Gitlein O (2004) The capacity of the Scintrex Autograv CG-3M no. 4492 gravimeter for "absolute-scale" surveys. Rev Brasil Cartografia (Brazil J Cartography) 56(2):89-95

Torge W (1989) Gravimetry. Walter de Gruyter, Berlin, New York

Van Camp M, Vanclooster M, Crommen O, Petermans $\mathrm{T}$, Verbeeck K, Meurers B, van Dam T, Dassargues A (2006) Hydrogeological investigations at the Membach station, Belgium, and application to correct long periodic gravity variations. J Geophys Res 111(B10403), doi:10.1029/2006JB004405

Virtanen H (2000) On the observed hydrological environmental effects on gravity at the Metsähovi station, Finland. Cahiers du Centre Européen de Géodynamique et de Séismologie 17:169-176

Virtanen H, Tervo M, Bilker-Koivula M (2006) Comparison of superconducting gravimeter observations with hydrological models of various spatial extents. Bulletin d'Information des Marées Terrestres 142:11,361-11,368
Vitushkin L, Becker M, Jiang Z, Francis O, van Dam TM, Faller J, Chartier JM, Amalvict M, Bonvalot S, Debeglia N, Desogus S, Diament M, Dupont F, Falk R, Gabalda G, Gagnon C, Gattacceca T, Germak A, Hinderer J, Jamet O, Jeffries G, Käker R, Kopaev A, Liard J, Lindau A, Longuevergne L, Luck B, Maderal E, Mäkinen J, Meurers B, Mizushima S, Mrlina J, Newell D, Origlia C, Pujol E, Reinhold A, Richard P, Robinson I, Ruess D, Thies S, Van Camp M, Van Ruymbeke M, de Villalta Compagni M, Williams S (2002) Results of the Sixth International Comparison of Absolute Gravimeters, ICAG-2001. Metrologia 39(5):407424, doi:10.1088/0026-1394/39/5/2

Wenzel HG (1993) Program package GRAVNA - Adjustment of gravity observations. Fortranprogram, Geodetic Institute, University Karlsruhe, unpublished

Wolf H (1997) Ausgleichsrechnung I, Formeln zur praktischen Anwendung, 3rd edn. Dümmlers, Bonn

Zerbini S, Richter B, Negusini M, Romagnoli C, Simon D, Domenichini F, Schwahn W (2001) Height and gravity variations by continuous GPS, gravity and environmental parameter observations in the southern Po Plain, near Bologna, Italy. Earth Planet Sci Lett 192(3):267-279, doi:10.1016/S0012-821X(01)00445-9 